\title{
Argentinean National Presentation
}

\author{
Esther Galina and Mónica Villarreal
}

In this text, we aim to offer a brief overview of education and mathematics education (ME) in Argentina and people and actions that have contributed to ME as it stands at present. It includes four topics: the characteristics of the current education system and some special programs, the popularization of mathematics and sciences, a brief reference to the mathematics teacher education system, and the development of mathematics and ME in the country.

\section{Argentinean Education System}

\section{Structure and Statistics}

Argentina is the second biggest country in South America; it consists of 23 provinces and an autonomous city, Buenos Aires. It has a population of 42 million people, with largest concentrations at the main cities. The total area of Argentina is $3,761,274 \mathrm{~km}^{2}$, and the continental area is $2,780,091 \mathrm{~km}^{2}$. The population according to the national census of 2010 was 40,117,096, with $30 \%$ between 0 and 17 years old, and the population density (excluding Antarctica) was 14.6 people per $\mathrm{km}^{2}$.

In spite of the difficulties that such a large country presented for education, universal first-level education for children was implemented in the 19th century in the entire territory. There were problems related to access in the fulfillment of this initiative in some sparsely populated regions and in certain social sectors,

\footnotetext{
E. Galina $(\bowtie)$

Unión Matemática Argentina (UMA), Consejo Nacional de Investigaciones Científicas y Técnicas (CONICET), Facultad de Matemática, Astronomía, Física y Computación, Universidad Nacional de Córdoba, Córdoba, Argentina e-mail: galina@famaf.unc.edu.ar 
necessitating implementation of a set of official policies to consolidate a universal thereby free compulsory education.

The current Argentinean education system has two main characteristics: It is universal and compulsory from kindergarten to secondary school. Kindergarten (2 years), primary (6 years), and secondary school (6 years) are compulsory. In Argentina, there are public and private schools. Compulsory education depends on each province and is free at public schools.

Since 1884, primary school has been universal, free, compulsory, and secular. In 1905, rural schools were created and boys and girls started sharing classes. In 1993, kindergarten (1 year) and the first three years of secondary school became also compulsory, for a total of 10 years of compulsory education. In 2006, the six years of secondary school became compulsory. Since 2015, one more year of kindergarten has been compulsory, for a total of 14 years of compulsory education.

Regarding the third and fourth education levels, $80 \%$ of the university students attend public (federal or provincial) universities. Argentinean public universities have been free for undergraduate studies since 1949. Their budget depends on the federal or state governments. They enjoy a very broad political autonomy, being self-governed mainly by professors and students. In mathematics, the undergraduate and graduate levels are well established and consolidated.

Although higher education levels are primarily concentrated at public or private universities, there are also many non-university tertiary public and private institutions. Many of them are devoted to teacher education.

Excluding university level, in 2014, 10,988,786 students were enrolled in formal common education (73\% in public schools), 128,966 in special education (78\% in public schools) and 1,240,496 in adult education ( $91 \%$ in public schools). In the same year, there were $1,871,445$ university students, with $78 \%$ studying at public universities. The number of graduate students at universities was of 144,229, with $77 \%$ enrolled in public institutions.

\section{Curricular Documents and Materials}

Regarding the many difficulties associated with a non-centralized education system, since each province is autonomous in relation to education, in 2005, the Federal Council of Education (consisting of the National and all the Provincial Ministries of Education, and three representatives from the Council of Universities) approved the Núcleos de Aprendizajes Prioritarios (NAP; "Priority Learning Cores") for primary school. A NAP is a body of knowledge that should be part of the education for all children because it has subjective and social significance and the potential to provide a common basis to reverse situations of injustice. NAP's objectives are to create equal opportunities for access to knowledge in order to contribute to the full social integration of children and to support values that favor the common benefit, social life, shared work, and respect of differences. More recently, NAP for secondary school were also produced. As complement of the NAP, the National 
Ministry of Education created the Cuadernos para el Aula, which include pedagogical orientations, discussions, and examples for teachers to approach the contents. Each provincial jurisdiction developed its curriculum based on NAP, its own policies, and contextual conditions.

The textbooks for compulsory education are predominantly published by private publishers, but the National Ministry of Education offers some orientations through the NAP and the Cuadernos para el aula for the teaching of mathematics at different levels of the compulsory educational system. Nevertheless, there are some official programs for distributing books at schools. Another important resource for teachers is National Ministry of Education's website (https://www.educ.ar/), which is oriented towards teachers, families, and students and contains teaching materials, blogs, news, activities, forums, suggestions, experiences, videos, etc.

Although we can say that there is an interesting set of non-compulsory teaching materials that encourage teachers to reflect on their practices and contribute concrete interesting activities, and although some of those materials emphasize the active role of the students as mathematics producers, this is not enough.

\section{Special Educational Programs}

Since 2003, the national government has implemented some special education programs such as the Centros de Actividades Infantiles (CAI; "Children's Activities Centers") and Centros de Actividades Juveniles (CAJ; "Youth Activities Centers"). In such centers, operating in public schools, systematic extracurricular activities of diverse types, such as cultural, artistic, recreational, collaborative, scientific, technological, and sportive activities, have been developed. In 2016, with a new government, the National Ministry of Education and Sports decided not to allocate more funds for these programs. Some provincial jurisdictions continue them using their own budgets.

Another important program was Mathematics for All (2010-2012), a program for training teachers and accompanying them during teaching. It was developed in 1700 primary schools and aimed to analyze teachers' practices and "do mathematics" at school using the NAP.

From our point of view, the most important special program has been Conectar Igualdad, which started in 2010. This national program aims at diminishing the digital gap among different population sectors. It includes the distribution of a netbook for each secondary school student and teacher and each student with special needs and their teachers in every public school in the country. As of July 2016, more than 5.5 million netbooks had been distributed. Some facts that contributed to the implementation of this program were the existence of diverse social, cultural, and economic conditions all over de country and the necessity of guarantying all students access to digital technologies (DT); the fact that the use of computers is a determinant for accessing some jobs; the lack of access to diverse sources of information; the fact that technological education does not only imply 
the use of computers; and the recognition that secondary education has more deficiencies than primary education.

The aims of the program are: (1) Reduce digital exclusion and marginality, (2) give students and teachers direct access to information without mediators, (3) incorporate DT for the construction of knowledge for different school subjects, and (4) improve the quality of public education.

The achievements of this program as of 2016 can be summarized as follows: improved technological literacy among teenagers and their families; greater access to information without mediators; and implementation of several courses for teachers, despite remaining difficulties in teaching with DT. The program installed discussions related to the use of technology in education and the relations among teachers, students, and families around this knowledge.

\section{Popularization of Mathematics and Sciences}

Mathematics competitions organized by the Argentinean Mathematical Olympiad (OMA) have had a strong presence in Argentina for many years but have currently lost some relevance. The popularization of mathematics has improved the last years. The effects of the popularization of mathematics accomplished by a variety of public programs and by Adrián Paenza ${ }^{1}$ during the last decade in Argentina have been very important. After him, people that had never been attracted by mathematics started to read mathematics books for fun. Radio and television programs conducted by him introduce discussions of mathematics topics, and mathematics facts are treated as curiosities to be elucidated. He has been an initiator of the popularization of science in Argentina.

Encuentro Channel, a television channel belonging to the National Ministry of Education, has been another important medium for popularizing mathematics and sciences since 2007. Its objectives are: (1) Contribute to equity in access to knowledge for all inhabitants of Argentina and the countries of the region regardless of their place of residence or social status, (2) provide schools with television contents and multimedia to improve the quality of education in Argentina, and (3) offer innovative materials to facilitate and improve the processes of teaching and learning in the context of the current challenges for education in order to collectively construct a more equitable society.

In 2011, an important science, technology, industry, and art mega-exhibition called Tecnópolis was inaugurated by the national government. It offers innovative materials to facilitate and improve the processes of teaching and learning in the context of the current challenges for education in order to collectively construct a more equitable society. Other science fairs have been organized by universities.

\footnotetext{
${ }^{1}$ Winner of the 2014 ICMI Leelavati prize for outstanding contributions to increasing public awareness of mathematics as an intellectual discipline and the crucial role it plays in diverse human endeavors.
} 
Popularization of mathematics has been possible thanks to national government policies designed to encourage the development of the sciences and technology and the democratization of scientific knowledge and to increase the number of scientists and science students. Argentina has started to change the scientific culture of its society.

\section{Teacher Education System}

Argentina has a number of non-university tertiary institutes and universities for teacher education. Kindergarten and primary school teachers are trained only in tertiary institutions. Secondary school mathematics teachers can study at tertiary institutions or at universities, but most attend non-university institutions. There are 193 tertiary institutes (149 are public) and 34 universities (29 are public) that train mathematics teachers for secondary school. The average number of graduates from each of the 193 non-university institutes in 2015 was 7.6. There is no data available for the average number of graduates from the 34 universities. There are substantial differences between the syllabuses at universities and tertiary institutions. New standards for mathematics teacher education at universities are currently being discussed.

Argentina has a mathematics teacher deficit, so some schools hire mathematics teachers who are students or people with professional degrees without pedagogical training.

\section{Mathematics and Mathematics Education in Argentina}

Figures 1 and 2 show timelines for the development of mathematics and ME in Argentina. They include the influence of great mathematicians such as Rey Pastor, Santaló, Levi, Monteiro, Villamayor, Calderón, and others.

Regarding ME, we can say that a mathematics education movement is developing in Argentina. Some of the evidence of this movement are:

- Creation of a variety of ME groups or associations. The Sociedad Argentina de Educación Matemática (SOAREM; "Argentinean Society of Mathematics Education") was created in 1998. The Argentinean Group of Mathematics Education (GAEM) was created in 2007. In 2015, the Argentinean Mathematical Union (UMA) created a special commission devoted to educational issues. In spite of the existence of these ME-related groups, we still do not have a comprehensive ME organization that includes everyone working in $\mathrm{ME}$ to coordinate objectives, actions, and meetings.

- Organization of diverse international and national ME meetings in Argentina, such as the XXVII Reunión Latinoamericana de Matemática Educativa (2013) and the VI Reunión de Didáctica de la Matemática del Cono Sur (2002). In the 


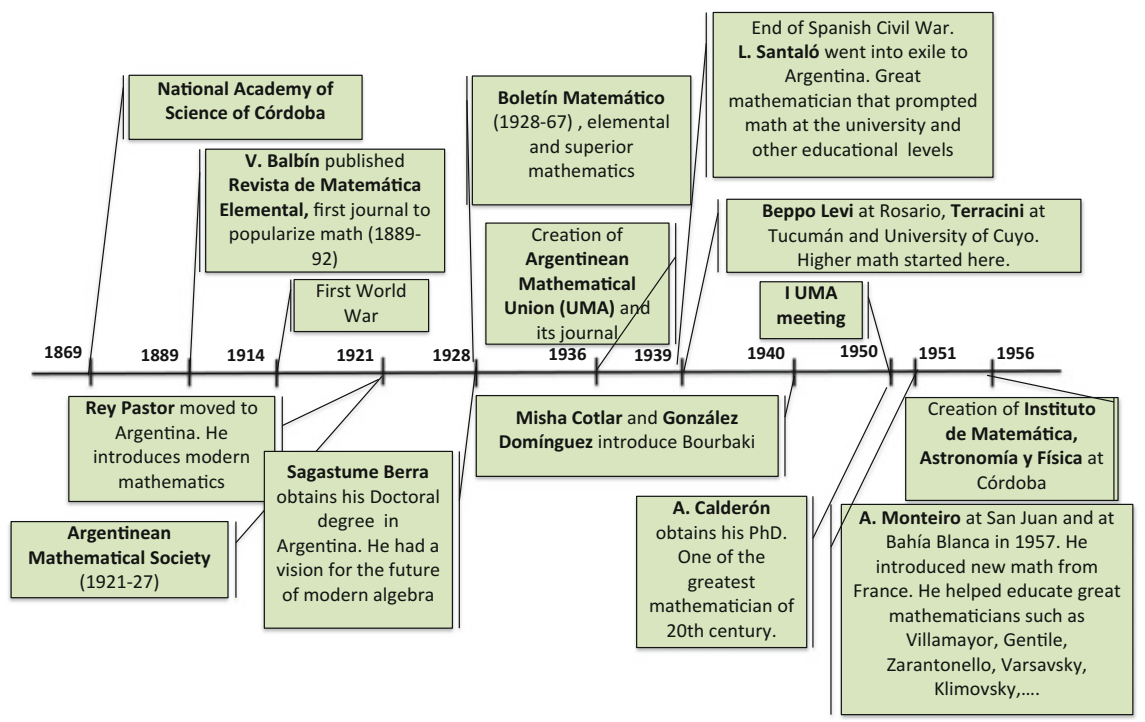

Fig. 1 Mathematics and ME in Argentina 1869-1956

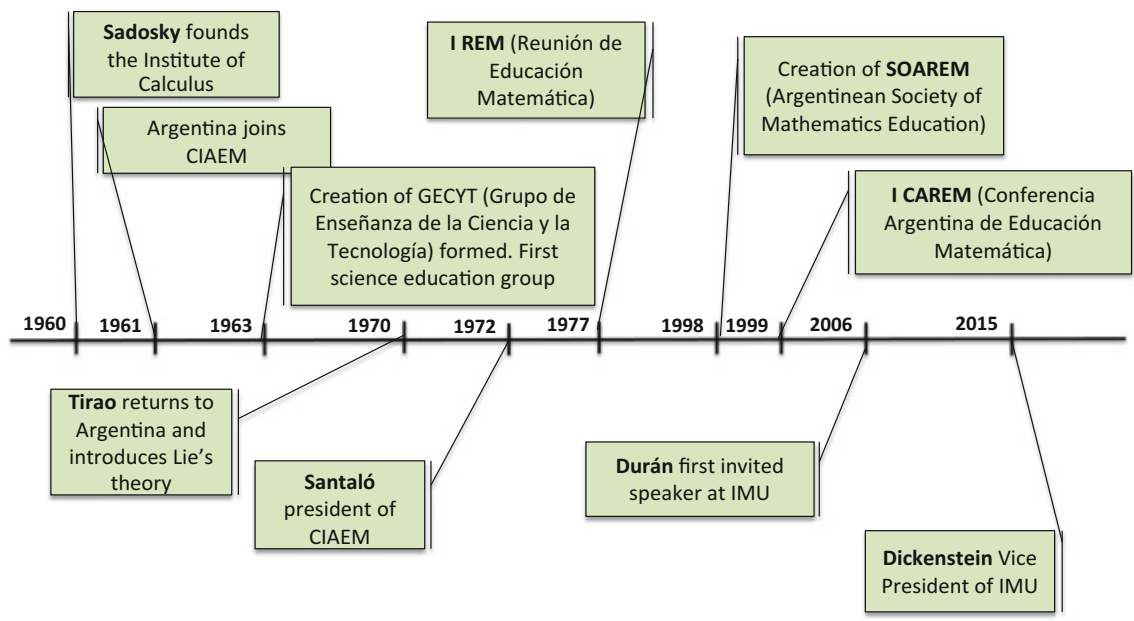

Fig. 2 Mathematics and ME in Argentina 1960-2015

local context, since 1977, UMA has annually organized the Reunión de Educación Matemática; since 1999, SOAREM has organized the Conferencia Argentina de Educación Matemática (12 meetings); since 2003, Jornadas de Educación Matemática by University of the Litoral (5 meetings); since 2000, the EDUMAT Civil Association has organized the Simposio de Educación Matemática (12 meetings); since 2005, the University of San Martín, University 
Arturo Jauretche, and UNIPE have organized 7 editions of the Escuela de Didáctica de la Matemática; and since 2006, the University of La Pampa has organized the Reunión Pampeana de Educación Matemática (6 meetings). These are just some examples of local meetings.

- Publication of local journals and books devoted to ME topics. Journals: Revista de Educación Matemática, UMA, since 1982; Revista Premisa, SOAREM, since 1999; and Revista Yupana, University of the Litoral, since 2004. Books: Collection about Mathematics Teacher Education edited by Libros del Zorzal since 2005.

- Creation of many master's degrees and recently some doctoral programs related to ME.

- Visit of foreign researchers.

- Increasing number of research groups related to $\mathrm{ME}$ at different universities and tertiary institutes.

- Increasing participation in international meetings with less attendance to congresses in which the official language is not Spanish: Congreso Iberoamericano de Educación Matemática (CIBEM), Reunión Latinoamericana de Matemática Educativa (RELME), and Conferencia Interamericana de Educación Matemática (CIAEM). At ICME-13, there were 38 Argentinean authors for 42 presentations.

\section{Final Remarks}

- The idea of a popular, universal, free, and compulsory education is deeply rooted in Argentina.

- Approximately $70 \%$ of all educational levels are public.

- Argentina has a high quality set of curricular materials and programs for the popularization of mathematics, but they are still unavailable to certain populations.

- It is necessary to qualitatively and quantitatively improve teacher education.

- Efforts to improve ME to date are still not sufficient.

- There is an increasing community of mathematicians at the international level.

- Mathematicians and mathematics educators are improving their relationships, and universities and non-university institutions in charge of mathematics teacher education are improving their relationships as well.

- Research in ME is increasing both qualitatively and quantitatively.

- Financial support for research in ME mainly comes from public universities. There is very little support from the most important agencies, possibly because in such agencies the evaluating commissions include non-specialists in science and mathematics education.

- It seems likely that a new educational policy started with the new government in December, 2015. There is an uncertainty about the continuity of the educational programs started during the previous government (2001-2015) and implemented for more than 10 years. 


\section{Bibliography}

Ministerio de Educación y Deportes. Dirección Nacional de Información y Estadística Educativa. Anuarios estadísticos. Argentina. http://portales.educacion.gov.ar/diniece/2014/05/24/anuariosestadisticos/. Retrieved April 5, 2017.

Ministerio de Educación y Deportes. Instituto Nacional de Formación Docente. Argentina. http:// portales.educacion.gov.ar/infd/. Retrieved April 5, 2017.

Ministerio de Educación y Deportes. Portal Educativo. Argentina. https://www.educ.ar/. Retrieved April 5, 2017.

Ministerio de Educación y Deportes. Secretaría de Políticas Universitarias. Departamente de Información Universitaria. Argentina. http://portales.educacion.gov.ar/spu/investigacion-yestadisticas/. Retrieved April 5, 2017.

Scaglia, S., \& Kiener, F. (2013). Aportes sobre el estado actual de la Educación Matemática en Argentina. Revista Binacional Brasil Argentina, 2(2), 25-47.

Sistema Federal de Medios y Contenidos Públicos. Encuentro. Canal de TV Educativo. Argentina. http://encuentro.gob.ar/. Retrieved April 5, 2017.

Sociedad Científica Argentina. (1972). In Evolución de las ciencias en la República Argentina, 1923-1972. Buenos Aires.

Villarreal, M., \& Esteley, C. (2002). Una caracterización de la Educación Matemática en Argentina. Revista de Educación Matemática, 17(2), 18-43.

Open Access Except where otherwise noted, this chapter is licensed under a Creative Commons Attribution 4.0 International License. To view a copy of this license, visit http://creativecommons. org/licenses/by/4.0/.

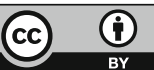

